\title{
Nota sobre abelhas Lestrimelitta rufipes (Freise) (Hymenoptera, Meliponina), atraídas por armadilhas com iscas odoríferas, na região Sul Fluminense do Estado do Rio de Janeiro
}

\author{
Luis Henrique Soares Alves ${ }^{1,5}$, Jorge Antonio de Lima Forny ${ }^{1}$, Paulo Cesar Rodrigues Cassino ${ }^{2,4}$, \\ Maria Cristina Affonso Lorenzon ${ }^{3}$,Francisco Racca-Filho ${ }^{4}$ \& Pedro Telles Ramos ${ }^{2}$ \\ ${ }^{1}$ Programa de Pós-graduação em Biologia Animal, Instituto de Biologia, \\ Universidade Federal Rural do Rio de Janeiro - UFRRJ, e-mail: jlforny@hotmail.com.br \\ ${ }^{2}$ Universidade Severino Sombra - USS, Vassouras, RJ, Brasil, \\ e-mails: pr.cassino@uol.com.br, ramos.ptelles@gmail.com \\ ${ }^{3}$ Departamento de Reprodução Animal, Instituto de Zootecnia, \\ Universidade Federal Rural do Rio de Janeiro - UFRRJ, e-mail: lorenzon@ ufrrj.br \\ ${ }^{4}$ Departamento de Entomologia e Fitopatologia, Instituto de Biologia, \\ Universidade Federal Rural do Rio de Janeiro - UFRRJ, e-mail: fraccafo@ ufrrj.br \\ ${ }^{5}$ Autor para correspondência: Luis Henrique Soares Alves, e-mail: Ihsalves@ hotmail.com
}

ALVES, L.H.S., FORNY, J.A.L., CASSINO, P.C.R., LORENZON, M.C.A., RACCA-FILHO, F. \& RAMOS, P.T. Note on bees Lestrimelitta rufipes (Friese) (Hymenoptera, Meliponina) attracted by scent traps in the South Region of the State of Rio de Janeiro. Biota Neotrop. 11(1): http://www.biotaneotropica.org.br/v11n1/ en/abstract?article+bn01311012011.

\begin{abstract}
This study was done each two months between August 2006 to May 2007 in a South Region in the State of Rio de Janeiro. The traps, a (Carvalho-47) model, were adjusted, then assembled at 9 o'clock and finally removed 48 hours after. In each place of the extraction, 4 traps were assembled, in a total of 20 in all the trail. During the experiment, eight worker bees of Lestrimelitta rufipes, were captured, and seven of them were attracted by methyl salicilate and one by cineole. Beside this essences, two more were used, eugenol and vanillin, but these two ones didn't collect any bees. All the bees were collected during November 2006. Even with such geographical distribution, L. rufipes hasn't been registered in this south region, and this is also the first registered collection of this specie using scent traps. It was not possible to identify the cause of the bee workers L. rufipes attraction by methyl salicilate and cineole, because these bees do not visit flowers, neither nets that could have this fragrance. The method of collection used by scent traps can be used for many purposes and among them the objective of knowing the richness and distribution of these types in different areas.
\end{abstract}

Keywords: cleptoparasitic bee, resource collection, survey, scent.

ALVES, L.H.S., FORNY, J.A.L., CASSINO, P.C.R., LORENZON, M.C.A., RACCA-FILHO, F. \& RAMOS, P.T. Nota sobre abelhas Lestrimelitta rufipes (Freise) (Hymenoptera, Apidae), atraídas por armadilhas com iscas odoríferas, na Região Sul Fluminense do Estado do Rio de Janeiro. Biota Neotrop. 11(1): http://www. biotaneotropica.org.br/v11n1/pt/abstract?article+bn01311012011.

Resumo: O estudo foi realizado bimestralmente entre agosto de 2006 e maio de 2007 na Região Sul Fluminense do Estado do Rio de Janeiro. As armadilhas, modelo Carvalho-47, foram adaptadas e posteriormente montadas às 9 horas e retiradas 48 horas depois. Em cada ponto de coleta foram montadas 4 armadilhas, totalizando 20 armadilhas em toda a trilha. Durante o experimento, oito operárias de Lestrimelitta rufipes (Friese) foram capturadas, sendo sete atraídas por salicilato de metila e uma por cineole. Além dessas essências, foram utilizadas mais duas essências, eugenol e vanilina, porém essas duas essências não atraíram nenhum indivíduo. Todas as abelhas foram coletadas ao longo de novembro de 2006. Mesmo com ampla distribuição geográfica, L. rufipes não havia sido registrada na região Sul Fluminense, sendo também o primeiro registro de coletas dessa espécie através de armadilhas com iscas odoríferas. Não foi possível identificar o porquê da atração das operárias de L. rufipes ao salicilato de metila e cineole, uma vez que essas abelhas não visitam flores nem ninhos que poderiam conter tais fragrâncias. O método de coleta através de armadilhas com iscas odoríferas poderá ser empregado com diversos objetivos, entre eles, o de conhecer a riqueza e a distribuição desse gênero em diversas áreas.

Palavras-chave: abelha cleptoparasita, coleta de recursos, levantamentos, odor. 


\section{Introdução}

Algumas abelhas eussociais podem parasitar ninhos de outras abelhas. Entre elas, encontra-se o gênero Lestrimelitta (Nogueira Neto 1997). As abelhas operárias desse grupo não possuem corbícula, possivelmente por perderem o comportamento de coletar e transportar pólen das flores (Michener 1990). Quando presente, a corbícula fica localizada na tíbia posterior e é destinada ao transporte de pólen e outros materiais utilizados na estrutura do ninho (Schwarz 1948, Moure 1951, Michener 1990). Por não possuírem corbículas, as lestrimelitas saqueiam ninhos de outras espécies de abelhas, vivendo à custa do mel, do pólen e da cera, armazenados nessas colmeias. Por esse motivo, elas são consideradas abelhas pilhadoras ou cleptobióticas (Roubik 1989, Wittmann et al. 1990). Ao saquear outras colmeias, as operárias liberam substâncias voláteis produzidas por suas glândulas mandibulares. Essas substâncias provocam a dispersão das abelhas da colmeia hospedeira, pois atuam na comunicação dessas abelhas, confundindo-as (Francke et al. 2000). Com isso, elas conseguem saquear os ninhos e armazenar o alimento nos papos para poderem transportá-lo até seus ninhos. De acordo com Nogueira-Neto (1997), o mel e o pólen produzidos pelas lestrimelitas podem ser perigosos se consumidos pelo homem, pois são considerados tóxicos, devido a secreções tóxicas de suas glândulas mandibulares. O comportamento cleptobiótico é considerado bioindicador de comunidades ricas em abelhas, pois os organismos que possuem esse comportamento vivem exclusivamente da pilhagem de outros ninhos, necessitando de áreas com grandes densidades de ninhos de outras espécies de abelhas para poderem sobreviver. O hábito de saquear alimento de outras espécies é encontrado também em Cleptotrigona e Trichotrigona (Michener 1990). As evidências indicam que tal comportamento pode ter evoluído de forma diferente nesses três grupos de abelhas (Michener 1990, Camargo \& Pedro 2003).

Lestrimelitta rufipes é uma abelha com ampla distribuição geográfica no território brasileiro, possuindo registros nos seguintes estados: Amazonas, Bahia, Ceará, Espírito Santo, Goiás, Maranhão, Mato Grosso, Minas Gerais, Pará, Paraná, Rio de Janeiro, Rio Grande do Sul, Rondônia, Roraima, Santa Catarina, São Paulo e Tocantins. (Marchi \& Melo 2006, Santanal et al. 2004). Mesmo com ampla distribuição geográfica, poucos trabalhos de levantamentos de lestrimelitas têm sido realizados e não são citados na literatura métodos de coletas específicos para esse grupo.

Diante disso, o presente trabalho objetivou descrever um novo método de amostragem de $L$. rufipes, utilizando iscas odoríferas.

\section{Materiais e Métodos}

O estudo foi realizado entre agosto de 2006 e maio de 2007, no Instituto Zoobotânico de Morro Azul (22 $22^{\circ}$ ' S e $43^{\circ} 34^{\prime}$ W), com área aproximada de 19 ha, que faz parte de um fragmento de Floresta Atlântica com aproximadamente 120 ha, localizado em Morro Azul, terceiro distrito do Município de Engenheiro Paulo de Frontin, região Sul Fluminense do Estado do Rio de Janeiro.

As armadilhas utilizadas no presente trabalho seguem o modelo Carvalho-47, desenvolvidas para coleta de coleópteros (Carvalho 1998). As mesmas foram adaptadas para coleta de abelhas euglossini. Essas armadilhas foram montadas bimensalmente, às 9 horas e retiradas 48 horas depois. Elas ficaram dispostas em cinco pontos, distantes uns dos outros $200 \mathrm{~m}$, todos eles localizados no interior do fragmento. Em cada ponto de coleta, foram montadas quatro armadilhas que ficavam distantes umas das outras, aproximadamente $3 \mathrm{~m}$, e a cerca de $1,5 \mathrm{~m}$ de altura do solo, totalizando 20 armadilhas em toda a trilha. Como atrativo às abelhas, foram utilizadas quatro fragrâncias: cineole, eugenol, salicilato de metila e vanilina. Em cada armadilha foram colocadas 10 gotas de cada tipo de fragrância. Essas fragrâncias são sintetizadas em laboratórios a partir de flores de orquídeas e outras fontes florais e são comumente utilizadas na atração de machos de abelhas Euglossini.
As abelhas coletadas estão montadas, identificadas e depositadas na Coleção Entomológica Costa Lima, do Instituto de Biologia (IB), da Universidade Federal do Rio de Janeiro (UFRRJ).

\section{Resultados e Discussão}

Durante o experimento, oito operárias de L. rufipes foram capturadas, sendo sete atraídas por salicilato de metila e uma por cineole. Todas as abelhas foram coletadas em novembro de 2006 . O ponto II, localizado na parte mais preservada do fragmento, coletou o maior número de abelhas (seis). Nos pontos I e IV houve a coleta de apenas uma abelha por ponto. Já nos pontos III e V, não ocorreu coleta de abelhas.

Criadores de melíponas da região de Engenheiro Paulo de Frontin relataram que os ataques de $L$. rufipes foram semelhantes aos descritos por Santanal et al. (2004), onde foi observado o ataque de Lestrimelitta limao (Smith) a ninhos de Tetragonisca angustula (Latreille), Nannotrigona testaceicornis (Lepeletier), Plebeia droryana (Friese), Friesella schrottkyi (Friese) e Friesiomelitta varia (Lepeletier). Na região de Engenheiro Paulo de Frontin, L. rufipes saqueou ninhos de quatro colônias de Tetragonisca angustula e de duas colônias de Nannotrigona testaceicornis. Durante o ataque de L. rufipes, uma colônia de Tetragonisca angustula foi completamente dizimada. Segundo o meliponicultor, essa colônia estava fraca e encontrava-se há pouco tempo em uma colmeia racional. Nos saques de L. rufipes aos ninhos de Nannotrigona testaceicornis não houve morte de nenhum ninho dessa espécie, porém, eles ficaram muito fracos após o saque. Ainda nessa localidade, foi encontrado um ninho de L. rufipes há aproximadamente 700 m do meliponário e a 1.500 m do local de coleta.

Apesar de sua ampla distribuição geográfica, L. rufipes não havia sido registrada na região Sul Fluminense do Estado do Rio de Janeiro, sendo esse seu primeiro registro e também o primeiro registro de coletas desta espécie através de armadilhas com iscas odoríferas. Essa nova ocorrência, através armadilhas com atrativos, é muito importante, principalmente por ser difícil o registro desse grupo, uma vez que tais abelhas, não possuem o hábito de visitar flores. Gonçalves \& Brandão (2008) coletaram três fêmeas de L. rufipes em área de Mata Atlântica no Norte do Estado do Rio de Janeiro, utilizando armadilha Malaise, que é um tipo de armadilha utilizada para interceptar o voo dos insetos através de uma barreira sem o uso de qualquer substância atrativa, como as iscas odoríferas.

Marchi \& Melo (2006) ao coletarem L. rufipes na região de BauruSP, não descreveram o método de coleta utilizado nos espécimes. É muito provável que não tenha sido através de substâncias atrativas, uma vez que não há registro de coleta de abelhas Lestrimelitta através de armadilhas que utilizam algum tipo de atrativo. Esses mesmos autores, ao revisarem o gênero Lestrimelitta, analisaram espécimes de diferentes localidades, com a maior parte das abelhas coletada por armadilha Malaise (Almeida et al. 1998).

Não foi possível identificar o porquê da atração das operárias de $L$. rufipes ao salicilato de metila e cineole e nem o porquê dessas abelhas serem coletadas somente no mês de novembro, já que elas não visitam flores em busca de alimento e nem ninhos que poderiam conter tais fragrâncias.

Caso as diferentes espécies presentes no gênero Lestrimelitta possuam hábitos semelhantes, conforme considerou Nogueira Neto (1997), outras espécies de Lestrimelitta poderão ser atraídas por armadilhas com iscas odoríferas. Sendo assim, esse método poderá ser empregado com diversos objetivos, entre eles, o de conhecer a riqueza e a distribuição desse gênero. Além disso, esse método poderá auxiliar os meliponicultores na escolha da área de instalação das colmeias de abelhas sem ferrão, ao prevenir a instalação de meliponário nas proximidades de colônias naturais de Lestrimelitta. 


\section{Referências Bibliográficas}

ALMEIDA, L.M., RIBEIRO-COSTA, C.S. \& MARINONI, L. 1998. Manual de coleta, conservação, montagem e identificação de insetos. Ribeirão Preto, Holos, 88p.

CAMARGO, J.M. F. \& PEDRO, S.R.M. 2003. Sobre as relações filogenéticas de Trichotrigona CAMARGO \& MOURE (Hymenoptera, Apidae, Meliponini). In Apoidea neotropica: homenagem aos 90 anos de Jesus Santiago Moure (G.A.R. Melo \& I. Alves-dos-Santos, eds.). Editora UNESC, Criciúma, p. 109-122.

CARVAlHO, A.G. 1998. Armadilha, modelo Carvalho-47. Fl. Amb., 5(1):225-227.

FRANCKE, W., LUBLKE, G., SCHODER, W., RECKZIEGEL, A., IMPERATRIZ-FONSECA, V., KLEINERT, A., ENGELS, E., HARTFELDER, K., RADTKE, R., ENGELS, W. 2000. Identification of oxygen containing volatiles in cephalic secretions of workers of Brazilian stingless bees. J. Braz. Chem, 11(6):562-571.

GONÇALVES, R.B., BRANDÃO, C.R.F. 2008. Diversity of bees (Hymenoptera, Apidae) along a latitudinal gradient in the Atlantic Forest. Biota Neotrop. 8(4):51-61.
MARCHI, P., MELO, G.A.R. 2006. Revisão taxonômica das espécies brasileiras de abelhas do gênero Lestrimelitta Friese (Hymenoptera, Apidae, Meliponina). Rev. Bras. Entomol. 50(1):6-30.

MICHENER, C.D. 1990. Classification of the Apidae (Hymenoptera). Univ. Kansas Sci. Bull 54:75-164.

MOURE, J.S. 1951. Nota sobre Meliponinae (Hymenoptera-Apoidea). Dusenia 2:25-70.

NOGUEIRA-NETO, P. 1997. Vida e criação de abelhas indígenas sem ferrão. Nogueirapis, São Paulo, 446p.

ROUBIK, D.W. 1989. Ecology and natural history of tropical bees. Cambridge University, Cambridge, 514p.

SCHWARZ, H.F. 1948. Stingless bees (Meliponidae) of the Western hemisphere. Bull. Amer. Mus. Nat. Hist. 90:1546.

SANTANAL, W.C., FREITAS, G.S., AKATSU, I.P. \& SOARES, A.E.G. 2004. Abelha Iratim (Lestrimelitta limao Smith: Apidae, Meliponinae), realmente é danosa às populações de abelhas? Necessita ser eliminada? Mensag. Doce 78.

WITTMANN, D., RADTKE, R., ZEIL, J., LUBKE, G., FRANCKE, W. 1990. Robber bees (Lestrimelitta limao) and their host chemical and visual cues in nest defense by Trigona (Tetragona) angustula (Apidae: Meliponinae). J. Chem. Ecol. 16(2):631-641. 